\title{
Ernährung und Akne - Was steckt dahinter?
}

\section{Pasta, Pizza, Pickel}

Der Konsum verschiedener Lebensmittel wie Milch oder Pizza kann zu insulinotropen, akneinduzierenden Effekten führen, die auf Signaltransduktionsebene molekularbiologisch erklärt werden können. Den Zusammenhang von Ernährung und Akne hat Prof. Dr. Bodo C. Melnik in einem kürzlich veröffentlichen Review dargestellt.

In den westlichen Industrienationen liegt die Prävalenz der Akne während der Adoleszenz inzwischen bei über $90 \%$. Bei weit über der Hälfte (64\%) überspannt die Akne die zweite Lebensdekade. Im dritten Lebensjahrzehnt sind noch rund $43 \%$ betroffen.

Die über Jahrzehnte geltende Definition einer selbstlimitierenden, androgeninduzierten Hauterkrankung der Pubertät scheint überholt. Vielmehr kann Akne als eine sich an der Haut manifestierende sichtbare systemische mTORC1 („mechanistic target of rapamycin complex 1")-induzierte Zivilisationskrankheit aufgefasst werden, wie molekularbiologische Arbeiten der letzten Jahre zunehmend belegen (zusammengefasst im Review von Melnik BC. Clin Cosmet Investig Dermatol 2015; 8:371-88).

\section{Überaktivierung durch westlichen Lebensstil}

Die Kinase mTORC1 ist der zentrale zelluläre Schalter der Proteinbiosynthese, Lipidbiosynthese, des Zellwachstums, der Zellproliferation und somit anaboler Stoffwechselvorgänge, die letztlich einen erhöhten BMI hervorrufen können. Eine Überaktivierung der Kinase erfolgt durch einen in den westlichen Ländern vorherrschenden Lebens- und Ernährungsstil mit hohem Fleischkonsum, einer hohen glykämischen Last sowie einem Übermaß an Milch und Milchprodukten.

Auf zellulärer Ebene erfolgt die Aktivierung der mTORC1-Kinase durch Glutamin, Palmitinsäure, essenzielle verzweigtkettige Aminosäuren, Insulin sowie IGF-1 (Insulin-artiger Wachstumsfaktor-1). Seit Längerem ist bekannt, dass IGF-1 der wichtigste Trigger für die Talgdrüsenlipid-Synthese ist und die sebozytäre Lipogenese induziert.

Eine ebenso wichtige Rolle spielt IGF-1 bei der Induktion des nukleären FoxO-
Exports. Die „Forkhead-box“-Transkriptionsfaktoren stellen eine Familie zentraler regulatorischer Proteine dar, die die Expression wichtiger Gene moduliert. Diese Gene sind an der Kontrolle des Zellzyklus, der DNA-Reparatur, der Apoptose, des oxidativen Stresses, der Zelldifferenzierung, des Glukosestoffwechsels und anderer Zellfunktionen maßgeblich beteiligt. Der resultierende nukleäre Export des meist genrepressiv wirkenden FoxO1 bewirkt eine „Freischaltung" der an der Akne beteiligten Zielgene und nukleären Rezeptoren.

Die physiologisch auftretende Insulinresistenz der Pubertät und der damit einhergehende nukleäre Mangel an FoxO1 werden durch insulinotrope Wachstumsfaktorsignale westlicher Ernährung weiter gesteigert.

Bereits 1999 betrachteten Deplewski und Rosenfeld die Rolle von IGF-1 bei der Entstehung von Akne als bedeutender als die der Androgene. Die ernährungswissenschaftlichen Erkenntnisse stehen im Einklang mit den bekannten androgenen Einflüssen auf die Entstehung von Akne. Nutritive Wachstumsfaktorsignale (Insulin/IGF-1) steigern durch nukleären FoxO1-Mangel die Transkriptionsaktivität des Androgenrezeptors; hierbei induzieren erhöhte IGF-1-Spiegel durch Aktivitätssteigerung der $5 \alpha$-Reduktase die periphere Konversion von Testosteron zum zehnfach potenteren Dihydrotestosteron.

\section{Zwei Stimuli zur Aktivierung des Rezeptors erforderlich}

Die Aktivierung des Androgenrezeptors erfordert also zwei Stimuli: die Bindung des Liganden (Androgen) und die Unterdrückung seines inhibitorisch wirksamen Ko-Regulators FoxO1.

Den meisten Dermatologen, so Melnik, sei die IGF-1-abhängige Signaltransduk-

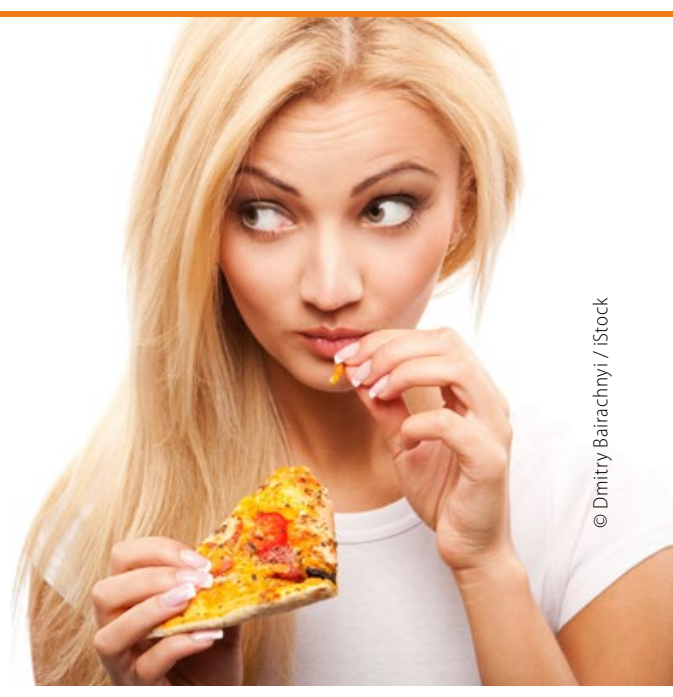

tion des Androgenrezeptors via FoxO1 nicht bewusst. Erst kürzlich wurde FoxO1 auch als ein Inhibitor des follikelstimulierendes Hormons sowie der LH(luteinisierendes Hormon)-Produktion erkannt.

Bestätigt wird die zentrale Rolle von IGF-1 beim Laron-Syndrom. Hier führt ein Gendefekt im Rezeptor des Wachstumshormons zu Kleinwüchsigkeit. Die IGF-1-Plasmaspiegel der Laron-Patienten sind deutlich erniedrigt. Unbehandelt (ohne IGF-1-Substitution) treten bei den Betroffenen keine Akne, kein Diabetes und nur selten Krebs auf.

\section{„Anti-Akne-Diät" beinhaltet viel Gemüse und Fisch}

Auch in einer 2014 veröffentlichten Untersuchung bei jungen Erwachsenen in New York zeigten Burris und Kollegen eine Assoziation zwischen dem Schweregrad einer Akne und der Menge aufgenommener gesättigter und trans-Fettsäuren sowie dem Zucker- und Milchkonsum.

Der Ernährungsstil der Industrieländer spielt bei der Entstehung von Akne die entscheidende Rolle, resümiert Melnik. Das Krankheitsbild verstärkt sich bei Vorliegen weiterer genetischer Defekte. Als „Anti-Akne-Diät“ empfiehlt er eine paläolithisch geprägte Ernährung mit dem Verzehr von Gemüse und Fisch und einen reduzierten Konsum von Zucker, hyperglykämischen Getreiden, Milch und Milchprodukten sowie gesättigter und trans-Fettsäuren. Günstig wirken $\omega$-3-Fettsäuren und pflanzliche Polyphenole, die mTORC1 hemmen.

(Ingo Schroeder)

Melnik BC. Clin Cosmet Investig Dermatol 2015; 8:371-88; Melnik BC, Schmitz G. Exp Dermatol 2013; 22:502-4; Melnik BC, Zouboulis CC. Exp Dermatol 2013;22:311-5 